\title{
Facile Synthesis of Electroconductive AZO@TiO Whiskers and Their Application in Textiles
}

\author{
Hui Ma, ${ }^{1,2}$ Qiang Gao, ${ }^{1,2,3}$ Chunxia Gao, ${ }^{3,4}$ Wei Bao, ${ }^{5}$ and Mingqiao Ge $e^{1,2}$ \\ ${ }^{1}$ Key Laboratory of Science and Technology of Eco-Textiles, Jiangnan University, Ministry of Education, Wuxi 214122, China \\ ${ }^{2}$ College of Textile \& Clothing, Jiangnan University, Wuxi 214122, China \\ ${ }^{3}$ State Key Laboratory of Molecular Engineering of Polymers, Department of Macromolecular Science and Laboratory of Advanced \\ Materials, Fudan University, Shanghai 200438, China \\ ${ }^{4}$ Institute of Orthopaedics, The First Affiliated Hospital of Soochow University, Suzhou 215006, China \\ ${ }^{5}$ Wuxi Entry-Exit Inspection and Quarantine Bureau, Wuxi 214101, China \\ Correspondence should be addressed to Qiang Gao; gaoqiang@jiangnan.edu.cn and Chunxia Gao; cxgao@suda.edu.cn
}

Received 3 February 2016; Revised 2 August 2016; Accepted 3 August 2016

Academic Editor: Reza Bayati

Copyright (c) 2016 Hui Ma et al. This is an open access article distributed under the Creative Commons Attribution License, which permits unrestricted use, distribution, and reproduction in any medium, provided the original work is properly cited.

\begin{abstract}
The electroconductive $\mathrm{AZO} @ \mathrm{TiO}_{2}$ whiskers have been successfully prepared via coating $\mathrm{Al}$ doped $\mathrm{ZnO}$ onto $\mathrm{TiO}_{2}$ whisker. The orthogonal tests were employed to optimize the synthetic conditions. The crystallographic structure and the morphology of the AZO@ $\mathrm{TiO}_{2}$ whiskers and the polypropylene nonwoven fabrics modified with $\mathrm{AZO} @ \mathrm{TiO}_{2}$ whiskers were characterized by Xray photoelectron spectroscopy, X-ray diffraction, scanning electron microscope, four-probe meter, and electrometer. The results showed the AZO@ $\mathrm{TiO}_{2}$ whiskers exhibited good electroconductive performance. Moreover, the polypropylene nonwoven fabrics modified with AZO@ $\mathrm{TiO}_{2}$ whiskers revealed excellent antistatic performance indicating wide application of $\mathrm{AZO} @ \mathrm{TiO}_{2}$ whiskers in the antistatic textiles.
\end{abstract}

\section{Introduction}

With the rapid development of nanotechnology, a great number of nanomaterials and nanostructures have been applied in diverse electronic and related fields. In recent years, many researchers have focused on the preparation of $\mathrm{TiO}_{2}$ with different morphologies for special functional applications [1], such as nanotubes [2], nanorods [3-5], and nanowires [6]. Rod-like $\mathrm{TiO}_{2}$ whiskers are more likely to disperse uniformly compared with nanoparticles, guaranteeing the good inner homogeneity [7]. Besides, the pathway for electron is readily formed as the rod materials overlap with each other, thus improving conductivity. However, the high electric resistance of $\mathrm{TiO}_{2}$ limits its application. One effective approach to reduce the electric resistance is to dope electroconductive elements onto $\mathrm{TiO}_{2}$ [8-10]. You et al. [11] prepared monodispersed $\mathrm{Cu}$-doped $\mathrm{TiO}_{2}$ nanorods with tunable lengths $(2-30 \mathrm{~nm})$, diameters $(2-5 \mathrm{~nm})$, and doping concentrations (1.7-3.2\%) through a low temperature hydrolytic route. The surface-functionalized method was employed to synthesize $\mathrm{TiO}_{2} @ \mathrm{CdS}$ core-shell nanorods using citric acid as an agent by Das and De [12]. Nevertheless, the reported works only focus on the photoelectron chemical behavior; the conductivity of the $\mathrm{TiO}_{2}$ whiskers coated with the conductive material has rarely been studied.

$\mathrm{Al}$ doped $\mathrm{ZnO}(\mathrm{AZO})$ is promising as a cost-effective replacement for other transparent conductors, such as $\operatorname{In}_{2} \mathrm{O}_{3}$ : $\mathrm{Sn}$ (ITO), $\mathrm{SnO}_{2}: \mathrm{Sb}$ (ATO), and $\mathrm{SnO}_{2}: \mathrm{F}$ (FTO), due to its high thermal stability, low price, and nontoxicity characteristics $[13,14]$. P-type doping of $\mathrm{ZnO}$ can be achieved via the addition of $\mathrm{Al}$ as the dopant [15]. AZO powders have been successfully prepared by a simple chemical coprecipitation method by Zhang et al. [16] and the photocatalytic and electrical properties were improved compared to those of $\mathrm{ZnO}$. Wu et al. synthesized aluminum and gallium codoped $\mathrm{ZnO}$ powders (AGZ), which led to fine grain size ranging 
from 14 to $28 \mathrm{~nm}$ and low resistivity of $2.518 \times 10^{3} \Omega \cdot \mathrm{cm}$ [17]. The conductivity is caused by the replacement of $\mathrm{Zn}^{2+}$ with $\mathrm{Al}^{3+}$, releasing excessive electrons into the conduction band.

In this study, the $\mathrm{Al}$ doped $\mathrm{ZnO}$ materials coatings onto $\mathrm{TiO}_{2}$ whiskers were synthesized by a facile hydrothermal method. The microstructure, morphology, and electrical performance of the AZO@ $\mathrm{TiO}_{2}$ whiskers were investigated. The properties of the polypropylene nonwoven fabrics modified with the AZO@TiO 2 whiskers were further studied.

\section{Experiment}

2.1. Materials. $\mathrm{TiO}_{2}$ nanoparticles with an average diameter of $250 \pm 35 \mathrm{~nm}$ were purchased from Jianghu Chemical Industry Co., Ltd., China. $\mathrm{Al}(\mathrm{NO})_{3} \cdot 9 \mathrm{H}_{2} \mathrm{O}, \mathrm{Zn}\left(\mathrm{NO}_{3}\right)_{2} \cdot 6 \mathrm{H}_{2} \mathrm{O}$, and $\mathrm{NaOH}$ were purchased from Sinopharm Chemical Reagent Co. Ltd., China. All the chemicals and reagents used in this study were of analytical grade.

\subsection{Preparation of Electroconductive AZO@TiO ${ }_{2}$ Whiskers}

2.2.1. Preparation of $\mathrm{TiO}_{2}$ Whiskers. The $\mathrm{TiO}_{2}$ whiskers were prepared by two-step synthesis. Generally, $\mathrm{TiO}_{2}$ nanoparticles and $\mathrm{K}_{2} \mathrm{CO}_{3}$ with the molar ratio of $n(\mathrm{Ti}) / n\left(\mathrm{~K}_{2} \mathrm{CO}_{3}\right)=$ 4 were firstly mixed in distilled water. After dispersing in ultrasonic cleaner $(100 \mathrm{~W})$ for $30 \mathrm{~min}$, the mixture was heated and blended with magnetic stirrer. When it became sticky, the dope was transferred into drying oven. After grinding process, the dried powders were performed in a muffle furnace at $1000^{\circ} \mathrm{C}$ for $10 \mathrm{~h}$ in order to form $\mathrm{K}_{2} \mathrm{Ti}_{4} \mathrm{O}_{9}$ whisker bunches and then boiled for $8 \mathrm{~h}$ in deionized water to disperse into the sole whiskers. After the $\mathrm{HCl}(60 \mathrm{~mol} / \mathrm{L})$ treatment for $6 \mathrm{~h}$ in the thermostatic water bath, the precursor was annealed at $1000^{\circ} \mathrm{C}$ for $5 \mathrm{~h}$ with the speed of $5^{\circ} / \mathrm{min}$ to obtain $\mathrm{TiO}_{2}$ whiskers.

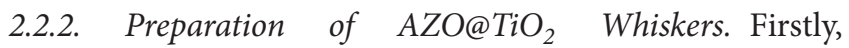
$\mathrm{Zn}\left(\mathrm{NO}_{3}\right)_{2} \cdot 6 \mathrm{H}_{2} \mathrm{O}$ was dissolved in distilled water with an amount of $\mathrm{Al}(\mathrm{NO})_{3} \cdot 9 \mathrm{H}_{2} \mathrm{O}$ further added into the $\mathrm{Zn}\left(\mathrm{NO}_{3}\right)_{2}$ solution to obtain the desired solution $\mathrm{A}$. The suspension was made with $\mathrm{TiO}_{2}$ nanoparticles and $100 \mathrm{~mL}$ distilled water. After the ultrasonic treatment for $30 \mathrm{~min}$, it was poured into a three-necked flask. A mixed acid solution of $\mathrm{A}$ was added to the suspension drop by drop at $65^{\circ} \mathrm{C}$ with stirring $(300 \mathrm{rpm})$. The $\mathrm{pH}$ value was maintained with the buffer solution during the process. After a 120 min reaction, the white precipitation was filtered and washed with distilled water and dried in a drying oven at $70^{\circ} \mathrm{C}$. After the sintering, the electroconductive AZO@ $\mathrm{TiO}_{2}$ whiskers were obtained.

2.3. Preparation of Antistatic Fabric. After cleaning with detergents and washed with distilled water, all the polypropylene nonwoven fabrics $(40 \mathrm{~cm} \times 45 \mathrm{~cm})$ were dried in the oven for $24 \mathrm{~h}$. The synthesized size, consisting of sticking agent (Guangdong Gongchenrihua Co., Ltd., China) and thickening agent (Shenzhen Yongzhiqiang Chemical Technology Co., Ltd., China), was mixed with $0.1,0.2,0.3,0.4$, and $0.5 \mathrm{wt} \%$ electroconductive AZO@ $\mathrm{TiO}_{2}$ whiskers. The polypropylene nonwoven fabrics were prepared with the mixture by surface coating manually. After coating, the fabrics were dried in vacuum oven for $1 \mathrm{~h}$.

2.4. Characterization. The $\mathrm{TiO}_{2}$ whiskers were fabricated from $\mathrm{TiO}_{2}$ and $\mathrm{K}_{2} \mathrm{CO}_{3}$ nanoparticles in a stable reactor, which could be heated up to $1000^{\circ} \mathrm{C}$ with a controllable heat rate of $10^{\circ} / \mathrm{min}$ by an automatic tube furnace (GSL 1600X, Hefei Kejing Materials Technology, China).

The morphology of the electroconductive AZO@ $\mathrm{TiO}_{2}$ whiskers was examined by scanning electron microscope (SEM) (SU-1510, Hitachi, Japan) operated at $10 \mathrm{kV}$. The samples were gold-sputtered on the surface to ensure the electrical conductivity and observed in vacuum environment to eliminate air impact. XRD analysis was performed using the X-ray powder diffraction (XRD) (D8 Advance, Bruker, Germany) with monochromated $\mathrm{Cu}-\mathrm{K} \alpha$ radiation $(\lambda=$ $1.54183 \AA$ ) across a $2 \theta$ range of $10-80^{\circ}$ with a rate of 0.1 s/step. The component of electroconductive AZO@ $\mathrm{TiO}_{2}$ whiskers was conducted with the $\mathrm{X}$-ray photoelectron spectroscopy (XPS) (ESCALAB 250Xi, Thermo Fisher Scientific, America), employing a soft X-ray source of Al-K $\alpha(h v=1486.6 \mathrm{eV})$ and operating at $150 \mathrm{~W}$.

The surface resistivity of the electroconductive AZO@TiO 2 whiskers was manifested by the four-probe meter (SZT-2A, Tongchuang Electronic, China). The antistatic property of nonwoven fabric was measured by fabric induced electrostatic measuring instrument (YG (B) 342D, Darong Textile Instrument, China).

\section{Results and Discussion}

3.1. Orthogonal Test for Electroconductive ${\mathrm{AZO} @ \mathrm{TiO}_{2}}$ Whiskers. Orthogonal design is one of the most effective and time-saving methods for the studies involving multiple variables in order to find out which factors (or variables) influence to the most extent properties of the target product [18]. Besides, it provides a powerful way to find an optimal combination of a smaller number of arrays to obtain the optimum thus reducing more experiments associated with the analysis [19, 20]. Based on our previous experimental results, the main factors, including calcination temperature, $\mathrm{pH}$, doping ratio $(\mathrm{Al} / \mathrm{Zn})$, and coating ratio $(\mathrm{Zn} / \mathrm{Ti})$, affected the formation process of electroconductive $\mathrm{AZO} @ \mathrm{TiO}_{2}$ whiskers. In this study, the $\mathrm{L}_{9}\left(2^{3}\right)$ orthogonal array of the Taguchi method [21] was adopted to investigate these factors and optimize the synthetic conditions. The factors and levels are listed in Table 1. Table 2 and Figure 1 present the experimental results of the $\mathrm{L}_{9}\left(2^{3}\right)$ orthogonal array. The surface resistivity of resultant AZO@ $\mathrm{TiO}_{2}$ whiskers was measured. The surface resistivity at level I for factor $A(B, C$, or $D$ ) is as follows:

$$
\begin{aligned}
K_{i A(B, C, \text { or } D)}= & \frac{\sum_{1}^{a}(b, c \text { or } d)}{n A(B, C \text { or } D)} \\
R_{A(B, C \text { or } D)}= & \max \left\{K_{i A(B, C, \text { or } D)}\right\} \\
& -\min \left\{K_{i A(B, C, \text { or } D)}\right\},
\end{aligned}
$$


TABLE 1: Factors and levels of orthogonal design.

\begin{tabular}{lcccc}
\hline Levels & $A$ & $B$ & $C$ & $D$ \\
Coating ratio/\% & Doping ratio/\% & \begin{tabular}{c} 
Calcination temperature $/{ }^{\circ} \mathrm{C}$ \\
\hline 1
\end{tabular} \\
\hline 45 & 2 & 8 & 400 \\
3 & 55 & 2.5 & 9 & 500 \\
\\
\hline
\end{tabular}

Symbols $A, B, C$, and $D$ represent factors of coating ratio, doping ratio, $\mathrm{pH}$, and calcination temperature. Symbols 1,2 , and 3 represent concentration levels of each factor.

TABLE 2: $\mathrm{L}_{9}\left(2^{3}\right)$ orthogonal array and experimental results.

\begin{tabular}{|c|c|c|c|c|c|}
\hline Trial number & $\begin{array}{c}A \\
\text { Coating ratio/at\% } \\
1 \\
\end{array}$ & $\begin{array}{c}B \\
\text { Doping ratio/at\% } \\
2 \\
\end{array}$ & $\begin{array}{c}\mathrm{C} \\
\mathrm{pH} \\
3\end{array}$ & $\begin{array}{c}D \\
\text { Calcination temperature } /{ }^{\circ} \mathrm{C} \\
4 \\
\end{array}$ & Surface resistivity $/(\mathrm{K} \Omega \cdot \mathrm{cm})$ \\
\hline 1 & $1(45)$ & $1(2)$ & $3(10)$ & $2(500)$ & 26.9 \\
\hline 2 & $2(55)$ & 1 & $1(8)$ & $1(400)$ & 8.7 \\
\hline 3 & $3(65)$ & 1 & $2(9)$ & $3(600)$ & 21.7 \\
\hline 4 & 1 & $2(2.5)$ & 2 & 1 & 4.3 \\
\hline 5 & 2 & 2 & 3 & 3 & 31.6 \\
\hline 6 & 3 & 2 & 1 & 2 & 5.0 \\
\hline 7 & 1 & $3(3)$ & 1 & 3 & 26.7 \\
\hline 8 & 2 & 3 & 2 & 2 & 39.7 \\
\hline 9 & 3 & 3 & 3 & 1 & 41.3 \\
\hline$K_{1}$ & 19.3 & 19.1 & 13.5 & 18.1 & - \\
\hline$K_{2}$ & 26.6 & 13.6 & 21.9 & 23.9 & - \\
\hline$K_{3}$ & 22.7 & 35.9 & 33.3 & 26.7 & - \\
\hline$R$ & 7.4 & 22.3 & 19.8 & 8.6 & - \\
\hline
\end{tabular}

The arrangements of columns $A, B, C$, and $D$ were decided by orthogonal design for 4 (factor) $* 9$ (run number); every row of run number represents one experimental replicate; every run was carried out twice.

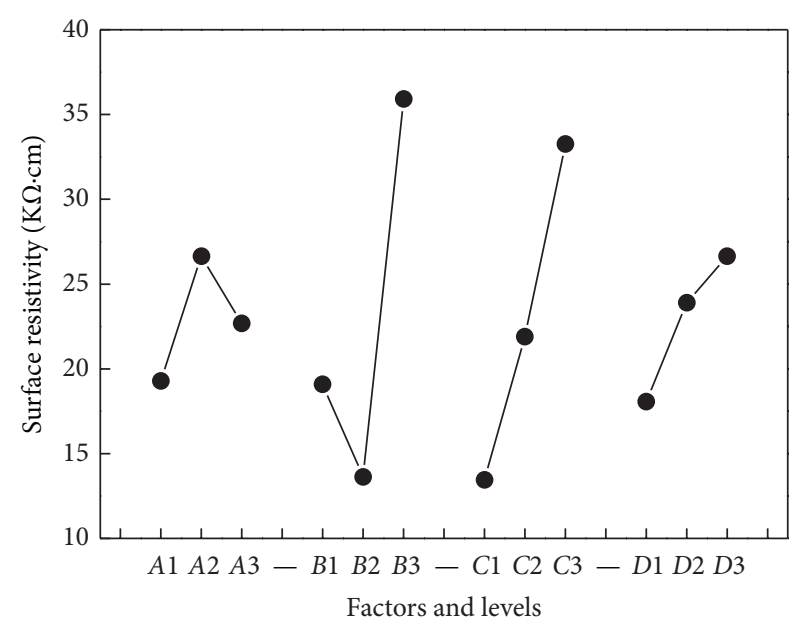

Figure 1: The trends between factors and levels and surface resistivity.

where $a, b, c$, and $d$ represent the numbers of levels for factors $A, B, C$, and $D$ and $R_{A}, R_{B}, R_{C}$, and $R_{D}$ represent the ranges, which affect the influences of levels on the experimental result.
TABLE 3: Coating ratio and surface resistivity.

\begin{tabular}{lcccc}
\hline Coating ratio/at $\%$ & 15 & 25 & 35 & 45 \\
\hline Surface resistivity $/ \mathrm{K} \Omega \cdot \mathrm{cm}$ & 98.9 & 65.3 & 41.6 & 36.5 \\
\hline
\end{tabular}

According to the value of $R$ in Table 2, the influence of four factors on the electroconductivity of AZO@ $\mathrm{TiO}_{2}$ whisker decreases in the order: doping ratio $>\mathrm{pH}>$ calcinations temperature $>$ coating ratio. Doping ratio and $\mathrm{pH}$ value are the dominant factors over others.

Our previous studies showed that the conductivity was enhanced with the increase of coating ratio $(\mathrm{Sn} / \mathrm{Ti})$ when $\mathrm{TiO}_{2}$ nanoparticles were encapsulated by ATO [22]. In this study, we continue to optimize the doping ratio to find the lowest surface resistivity as shown in Table 3 . The lowest surface resistivity was approached when the coating ratio was 45 at $\%$. Nevertheless, when the coating ratio continues to increase, the electroconductivity was deteriorated, which indicates that the coating ratio has been saturated.

In the factor of doping ratio, the surface resistivity of $\mathrm{AZO} @ \mathrm{TiO}_{2}$ whiskers decreases at first and then increases steadily at the optimal level of $2.5 \mathrm{at} \% . \mathrm{Al}^{3+}$ is ready to substitute $\mathrm{Zn}^{2+}$ position to form negatively charged lattice 


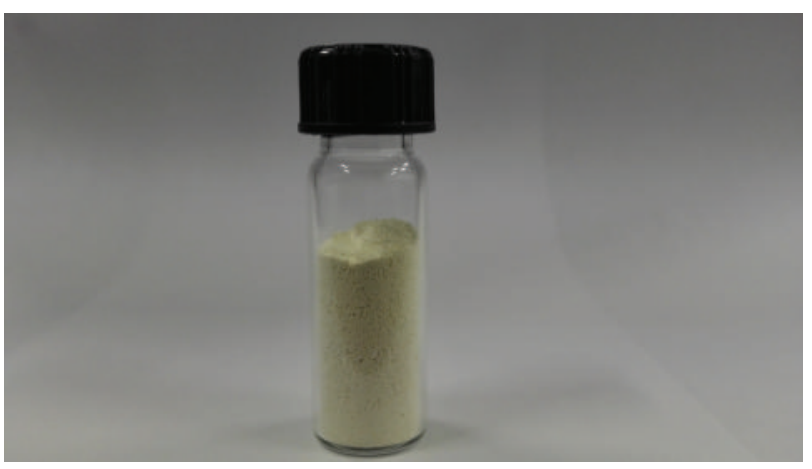

(a)

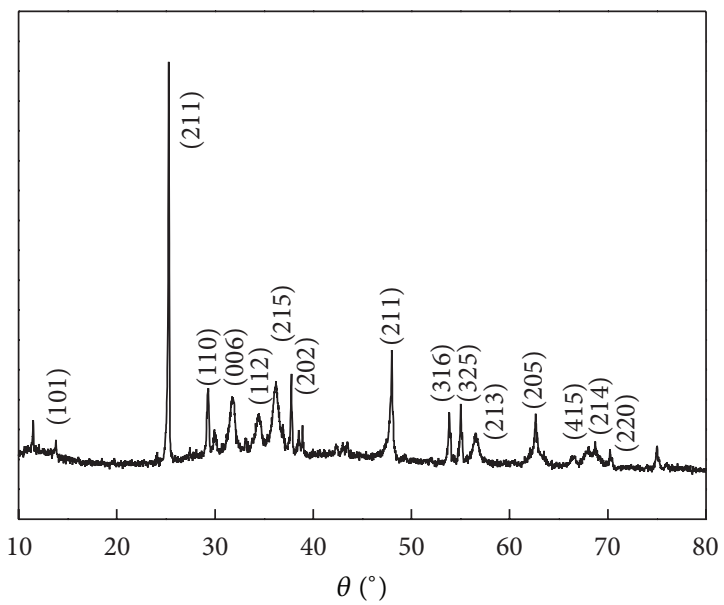

(c)

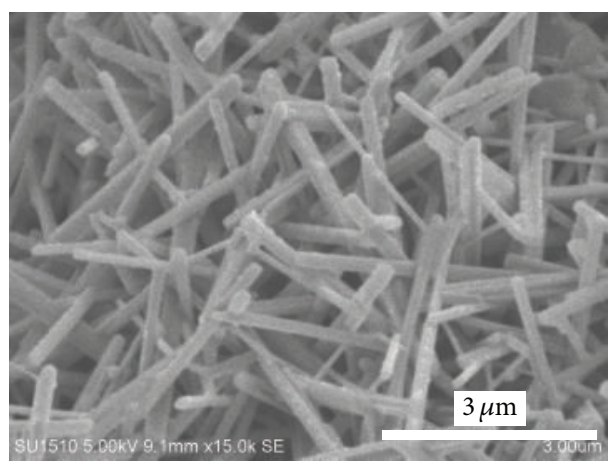

(b)

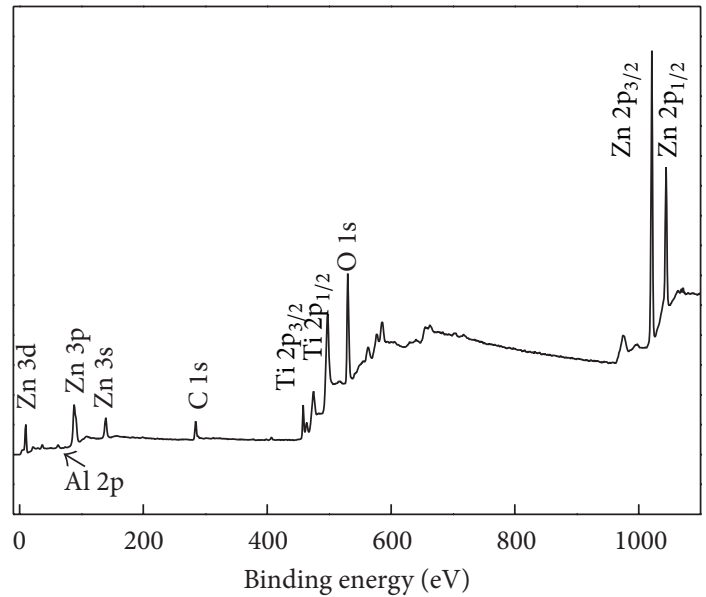

(d)

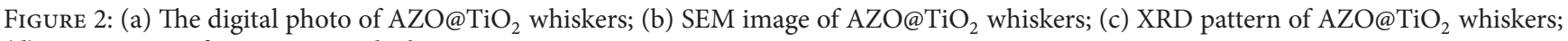
(d) XPS pattern of AZO@ $\mathrm{TiO}_{2}$ whiskers.

defects as the radius of $\mathrm{Al}^{3+}$ is smaller than $\mathrm{Zn}^{2+}$. Therefore, a free electron emerges. The conductivity would increase with the implement of $\mathrm{Al}^{3+}$ contents when doping ratio is below 2.5 at $\%$. The excess $\mathrm{Al}$ would form $\mathrm{ZnAl}_{2} \mathrm{O}_{3}$ rather than replace $\mathrm{Zn}^{2+}$ lattice site, which increases the resistivity. According to the report of Chen et al. [23] and Lu et al. [24], $\mathrm{ZnAl}_{2} \mathrm{O}_{4}$ would lead to the increasing resistivity of AZO.

The $\mathrm{pH}$ value also has a big impact on the conductivity of $\mathrm{AZO} @ \mathrm{TiO}_{2}$ whiskers, as it offers the opportunities for the suitable reactive environment. According to reaction equation (2), $\mathrm{Zn}(\mathrm{OH})_{4}{ }^{2-}$ is prepared in alkaline conditions and uniformly coated on the surface of $\mathrm{TiO}_{2}$ whiskers. With further dehydration reaction, the $\mathrm{H}_{2} \mathrm{O}$ is removed as shown in reaction equation (3):

$$
\begin{aligned}
\mathrm{Zn}^{2+}+2 \mathrm{OH}^{-}+2 \mathrm{H}_{2} \mathrm{O} & \longrightarrow \mathrm{Zn}(\mathrm{OH})_{4}{ }^{2-}+2 \mathrm{H}^{+} \\
\mathrm{OH}^{-}+\mathrm{OH}^{-} & \longrightarrow \mathrm{H}_{2} \mathrm{O}+\mathrm{O}_{2}{ }^{-}
\end{aligned}
$$

The influences of calcination temperature and coating ratio are relatively small that the resistivity fluctuated between $18 \mathrm{~K} \Omega \cdot \mathrm{cm}$ and $26 \mathrm{~K} \Omega \cdot \mathrm{cm}$. The optimal condition of resistivity was as follows: doping ratio $=2.5$ at $\%, \mathrm{pH}=8$, calcination temperature $=400^{\circ} \mathrm{C}$, and coating ratio $=45$ at $\%$. Due to the fact that the optimal experiment is out of nine groups in Table 2, we carried out another experiment according to the optimal condition and minimal surface resistivity of $3.6 \mathrm{~K} \Omega \cdot \mathrm{cm}$ was approached.

3.2. Properties of Electroconductive $A Z O @ \mathrm{TiO}_{2}$ Whiskers. The electroconductive $\mathrm{AZO} @ \mathrm{TiO}_{2}$ whiskers are yellow in color and small in size, as revealed in Figure 2(a). Figure 2(b) shows the SEM image of AZO@ $\mathrm{TiO}_{2}$ whiskers. AZO@ $\mathrm{TiO}_{2}$ whiskers are rod-like, with a diameter of $280-340 \mathrm{~nm}$ and a length of $1.95-3.75 \mu \mathrm{m}$. Furthermore, coating layer of AZO locates on the surface of $\mathrm{TiO}_{2}$ whiskers, where the electrons could be freely spread among whiskers when they are connected with each other and readily conduct electricity within the materials.

Figure 2(c) reveals the XRD pattern of synthetic whiskers. The characteristic peaks of rutile $\mathrm{TiO}_{2}$ (JCPDS no. 65-5714) can be clearly observed from the XRD pattern of AZO@ $\mathrm{TiO}_{2}$ whiskers [25]. Meanwhile, hexagonal wurtzite zincite peaks [26] (namely, $2 \theta=28.3^{\circ}, 31.4^{\circ}, 47.7^{\circ}$ ) were also observed, indicating that the $\mathrm{AZO}$ has been deposited onto the $\mathrm{TiO}_{2}$ whisker.

XPS analysis was employed to further confirm the chemical composition of the synthetic whiskers. Figure 2(d) illustrates that synthetic whiskers consist of $\mathrm{Zn}, \mathrm{Cls}, \mathrm{O}$, 


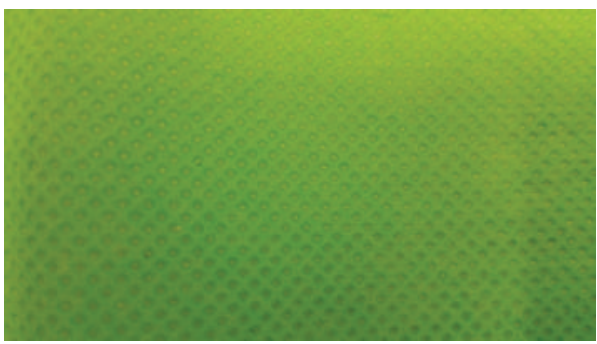

(a)

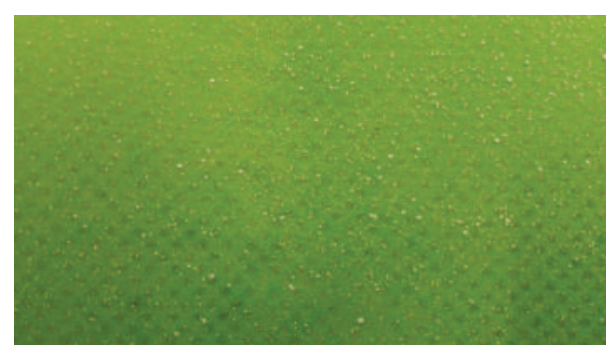

(b)

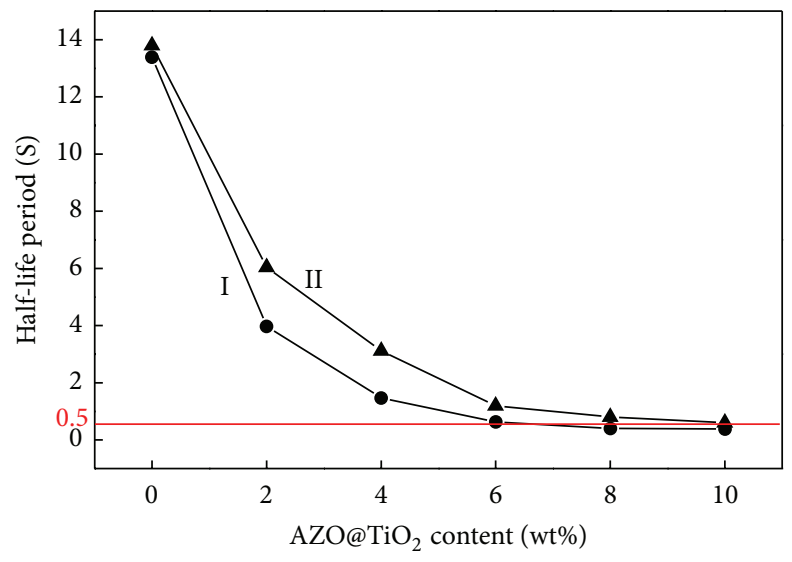

(c)

FIGURE 3: (a) Pure polypropylene nonwoven fabrics; (b) polypropylene nonwoven fabrics coated with $\mathrm{AZO} @ \mathrm{TiO}_{2}$ whiskers; (c) the

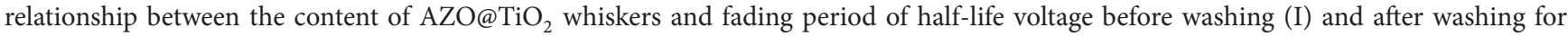
20 times (II).

and Ti elements. Among them, the binding energy of $\mathrm{C} 1 \mathrm{~s}$ peak was at $284.8 \mathrm{eV}$ and used as the reference standard. With scanning over the corresponding XPS spectra area, the binding energies for the $\mathrm{Zn} 2 \mathrm{p}$ region at around $1000 \mathrm{eV}$ were analyzed. The peak located at $1044.43 \mathrm{eV}$ was the same as $\mathrm{Zn}$ $2 \mathrm{p}_{3 / 2}$ and the other one located at $1021.53 \mathrm{eV}$ was assigned to $\mathrm{Zn} 2 \mathrm{p}_{1 / 2}$, while those of $\mathrm{Zn} 3 \mathrm{~d}, \mathrm{Zn} 3 \mathrm{p}$, and $\mathrm{Zn} 3 \mathrm{~s}$ were located at $10.08 \mathrm{eV}, 88.08 \mathrm{eV}$, and $139.08 \mathrm{eV}$, respectively. These peak positions agree with the reference values, suggesting a normal state of AZO in $\mathrm{AZO} @ \mathrm{TiO}_{2}$ whisker $[27,28]$. The binding energy of $\mathrm{O} 1 \mathrm{~s}$ peak was at $530.08 \mathrm{eV}$, clarifying the existence of $\mathrm{TiO}_{2}$ whisker. The $\mathrm{Ti} 2 \mathrm{p}_{3 / 2}$ and $\mathrm{Ti} 2 \mathrm{p}_{1 / 2}$ peaks also had obvious double peaks at binding energies of $458.53 \mathrm{eV}$ and $475.33 \mathrm{eV}$, respectively, indicting a normal state of $\mathrm{TiO}_{2}$ in AZO@ $\mathrm{TiO}_{2}$ whisker [5].

3.3. Antistatic Fabric Coated with AZO@TiO ${ }_{2}$ Whiskers. The coating method is of special interest in fabrication of nanostructured materials such as nanocomposite coatings carrying a variety of functionalities [29]. A layer of electroconductiveAZO@TiO ${ }_{2}$ whiskers was coated on the surface of polypropylene nonwoven fabrics. Compared with the uncoated polypropylene nonwoven fabrics in Figure 3(a), the electroconductive $\mathrm{AZO} @ \mathrm{TiO}_{2}$ whiskers were coated onto the surface (Figure 3(b)). The influence of the content of AZO@ $\mathrm{TiO}_{2}$ whiskers on the antistatic property of fabrics was shown in Figure 3(c)I. With increased AZO@ $\mathrm{TiO}_{2}$ whiskers, the half-life voltage of fabrics decreased sharply at first. When the content is more than $4 \mathrm{wt} \%$, the tendency to decrease is slow, and the half-life voltage drops to $1.47 \mathrm{~s}$. This suggests that the modified fabrics have good antistatic property. When the content is $8 \mathrm{wt} \%$, the half-life voltage is $0.401 \mathrm{~s}(<0.5)$, which indicates that the coated fabrics reach the index of excellent antistatic property (the red line). Meanwhile, antistatic property after washing is very important for surface-modified fabrics. If it is poor, the antistatic property does not remain for long [30]. Changes in the half-life voltage with different amount of AZO@ $\mathrm{TiO}_{2}$ whiskers after washing for 20 times are shown in Figure 3(c)II, similar to Figure 3(c)I. In addition, when the content of $\mathrm{AZO} @ \mathrm{TiO}_{2}$ whiskers reached $10 \mathrm{wt} \%$, the half-life voltage of surface-modified fabrics after washing for 20 times was $0.481 \mathrm{~s}(<0.5)$ still meeting the requirement of excellent antistatic property.

The application of fiber materials is limited in some particular environment due to the high resistance. The electroconductive AZO@ $\mathrm{TiO}_{2}$ whiskers with unique rodshaped structure and excellent conductivity own a wide future application in the functional textiles.

\section{Conclusion}

In summary, the rod-like electroconductive $\mathrm{AZO} @ \mathrm{TiO}_{2}$ whiskers were successfully fabricated by coating Al doped $\mathrm{ZnO}$ onto $\mathrm{TiO}_{2}$ whiskers. The optimal synthetic condition 
for electroconductive AZO@ $\mathrm{TiO}_{2}$ whiskers was obtained with doping ratio of 2.5 at $\%, \mathrm{pH}$ value of 8 , calcination temperature of $400^{\circ} \mathrm{C}$, and coating ratio of $45 \mathrm{at} \%$. The electroconductive AZO@ $\mathrm{TiO}_{2}$ whiskers are light yellow with a length to diameter ratio of 5.6. The polypropylene non-

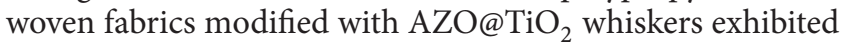
excellent antistatic performance and laundering durability,

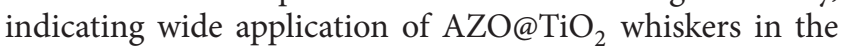
antistatic textiles.

\section{Competing Interests}

The authors declare that they have no competing interests.

\section{Acknowledgments}

The authors acknowledge financial support from Natural Science Foundation of China (Grant no. 21504033), China Postdoctoral Science Foundation (Grant no. 2015M580296), State Key Laboratory of Molecular Engineering of Polymers (Fudan University) (Grant no. K2016-04), Fundamental Research Funds for the Central Universities of China (no. JUSRP11444), the Research Project of Jiangsu Entry-Exit Inspection and Quarantine Bureau (Grant no. 2015KJ18), Jiangsu Province Key Laboratory of Silk Engineering (Grant no. KJS1413) and Open Project Program of Key Laboratory of Eco-Textiles, Jiangnan University, Ministry of Education (Grant no. KLET1403), Fundamental Research Funds for Graduate Education Innovation Project of Jiangsu Province in 2015 (no. SJZZ15_0146), and a project funded by the Priority Academic Program Development of Jiangsu Higher Education Institutions.

\section{References}

[1] T. Leshuk, R. Parviz, P. Everett, H. Krishnakumar, R. A. Varin, and F. Gu, "Photocatalytic activity of hydrogenated $\mathrm{TiO}_{2}$," ACS Applied Materials \& Interfaces, vol. 5, no. 6, pp. 1892-1895, 2013.

[2] P. Roy, S. Berger, and P. Schmuki, " $\mathrm{TiO}_{2}$ nanotubes: synthesis and applications," Angewandte Chemie-International Edition, vol. 50, no. 13, pp. 2904-2939, 2011.

[3] I. S. Cho, Z. Chen, A. J. Forman et al., "Branched $\mathrm{TiO}_{2}$ nanorods for photoelectrochemical hydrogen production," Nano Letters, vol. 11, no. 11, pp. 4978-4984, 2011.

[4] T. A. Kandiel, R. Dillert, A. Feldhoff, and D. W. Bahnemann, "Direct synthesis of photocatalytically active rutile $\mathrm{TiO}_{2}$ nanorods partly decorated with anatase nanoparticles," Journal of Physical Chemistry C, vol. 114, no. 11, pp. 4909-4915, 2010.

[5] J.-N. Nian and H. Teng, "Hydrothermal synthesis of singlecrystalline anatase $\mathrm{TiO}_{2}$ nanorods with nanotubes as the precursor," The Journal of Physical Chemistry B, vol. 110, no. 9, pp. 4193-4198, 2006.

[6] H.-W. Shim, D. K. Lee, I.-S. Cho, K. S. Hong, and D.-W. Kim, "Facile hydrothermal synthesis of porous $\mathrm{TiO}_{2}$ nanowire electrodes with high-rate capability for Li ion batteries," Nanotechnology, vol. 21, no. 25, Article ID 255706, 2010.

[7] H. Zhu, T. Jie, and D. Xiang, "Preparation and photoelectrochemical activity of Cr-doped $\mathrm{TiO}_{2}$ nanorods with nanocavities," The Journal of Physical Chemistry C, vol. 114, no. 7, pp. 2873-2879, 2010.
[8] S. Park, S.-D. Seo, S. Lee et al., "Sb:SnO $\mathrm{Sn}_{2} \mathrm{TiO}_{2}$ heteroepitaxial branched nanoarchitectures for Li ion battery electrodes," The Journal of Physical Chemistry C, vol. 116, no. 41, pp. 21717-21726, 2012.

[9] M. Xu, P. Da, H. Wu, D. Zhao, and G. Zheng, "Controlled Sndoping in $\mathrm{TiO}_{2}$ nanowire photoanodes with enhanced photoelectrochemical conversion," Nano Letters, vol. 12, no. 3, pp. 1503-1508, 2012.

[10] Q. Liu, L. Zhang, J.-F. Chen, and Y. Le, "Synthesis of TiO $\mathrm{T}_{2} @ \mathrm{ATO}$ core-shell nanofibers using coaxial electrospinning," Materials Letters, vol. 137, pp. 339-342, 2014.

[11] M. You, T. G. Kim, and Y.-M. Sung, "Synthesis of Cu-doped $\mathrm{TiO}_{2}$ nanorods with various aspect ratios and dopant concentrations," Crystal Growth and Design, vol. 10, no. 2, pp. 983-987, 2009.

[12] K. Das and S. K. De, "Optical properties of the type-II core-shell $\mathrm{TiO}_{2} @ \mathrm{CdS}$ nanorods for photovoltaic applications," The Journal of Physical Chemistry C, vol. 113, no. 9, pp. 3494-3501, 2009.

[13] S. Vunnam, K. Ankireddy, J. Kellar, and W. Cross, "Environmental stability of solution processed Al-doped $\mathrm{ZnO}$ naoparticulate thin films using surface modification technique," Applied Surface Science, vol. 322, pp. 1-5, 2014.

[14] Y.-S. Luo, J.-P. Yang, X.-J. Dai, Y. Yang, and S.-Y. Fu, "Preparation and optical properties of novel transparent al-doped$\mathrm{ZnO} /$ epoxy nanocomposites," The Journal of Physical Chemistry C, vol. 113, no. 21, pp. 9406-9411, 2009.

[15] Q. X. Xia, K. S. Hui, K. N. Hui et al., "High quality ptype N-doped AZO nanorod arrays by an ammonia-assisted hydrothermal method," Materials Letters, vol. 78, pp. 180-183, 2012.

[16] P. Zhang, R. Y. Hong, Q. Chen, and W. G. Feng, "On the electrical conductivity and photocatalytic activity of aluminum-doped zinc oxide," Powder Technology, vol. 253, pp. 360-367, 2014.

[17] R. Wu, W. Zhang, H. Zhang et al., "Investigation of aluminum and gallium co-doped $\mathrm{ZnO}$ powders and their effects on the properties of targets," Materials Science in Semiconductor Processing, vol. 19, no. 1, pp. 24-31, 2014.

[18] M. Dargahi, H. Kazemian, M. Soltanieh, M. Hosseinpour, and S. Rohani, "High temperature synthesis of SAPO-34: applying an L9 Taguchi orthogonal design to investigate the effects of experimental parameters," Powder Technology, vol. 217, pp. 223230, 2012.

[19] S. Ma, H. Wang, Y. Wang, H. Bu, and J. Bai, "Bio-hydrogen production from cornstalk wastes by orthogonal design method," Renewable Energy, vol. 36, no. 2, pp. 709-713, 2011.

[20] S.-Q. Liu, C.-F. Dai, L. Wang, S.-P. Li, and X.-D. Li, "Orthogonal test design for optimization of synthesis of MTX/LDHs hybrids by ion-exchange method," Journal of Physics and Chemistry of Solids, vol. 79, pp. 82-88, 2015.

[21] M. Olivia and H. Nikraz, "Properties of fly ash geopolymer concrete designed by Taguchi method," Materials and Design, vol. 36, pp. 191-198, 2012.

[22] Q. Gao, H. Ma, W. Bao, C. Gao, and M. Ge, "Polyacrylonitrile/electroconductive $\mathrm{TiO}_{2}$ nanoparticles composite fibers via wet-spinning," Fibers and Polymers, vol. 17, no. 7, pp. 1048-1054, 2016.

[23] Z. Chen, G. Zhan, Y. Wu, X. He, and Z. Lu, "Sol-gel-hydrothermal synthesis and conductive properties of Al-doped $\mathrm{ZnO}$ nanopowders with controllable morphology," Journal of Alloys and Compounds, vol. 587, pp. 692-697, 2014. 
[24] Z. Lu, J. Zhou, A. Wang, N. Wang, and X. Yang, "Synthesis of aluminium-doped $\mathrm{ZnO}$ nanocrystals with controllable morphology and enhanced electrical conductivity," Journal of Materials Chemistry, vol. 21, no. 12, pp. 4161-4167, 2011.

[25] M. Osada, M. Kobayashi, and M. Kakihana, "Enhanced dielectric response induced by controlled morphology in rutile $\mathrm{TiO}_{2}$ nanocrystals," Journal of the Ceramic Society of Japan, vol. 121, no. 1416, pp. 593-597, 2013.

[26] Y. Zhang, Y. Yang, J. Zhao et al., "Optical and electrical properties of aluminum-doped zinc oxide nanoparticles," Journal of Materials Science, vol. 46, no. 3, pp. 774-780, 2011.

[27] X. Q. Wei, B. Y. Man, M. Liu, C. S. Xue, H. Z. Zhuang, and C. Yang, "Blue luminescent centers and microstructural evaluation by XPS and Raman in $\mathrm{ZnO}$ thin films annealed in vacuum, $\mathrm{N}_{2}$ and $\mathrm{O}_{2}$," Physica B: Condensed Matter, vol. 388, no. 1-2, pp. 145152, 2007.

[28] X. Tian, Z. Pan, H. Zhang et al., "Growth and characterization of the Al-doped and Al-Sn co-doped $\mathrm{ZnO}$ nanostructures," Ceramics International, vol. 39, no. 6, pp. 6497-6502, 2013.

[29] M. Jafari, A. Rahimi, P. Shokrolahi, and A. E. Langroudi, "Synthesis of antistatic hybrid nanocomposite coatings using surface modified indium tin oxide (ITO) nanoparticles," Journal of Coatings Technology Research, vol. 11, no. 4, pp. 587-593, 2014.

[30] D. Wang, Y. Lin, Y. Zhao, and L. Gu, "Polyacrylonitrile fibers modified by nano-antimony-doped tin oxide particles," Textile Research Journal, vol. 74, no. 12, pp. 1060-1065, 2004. 

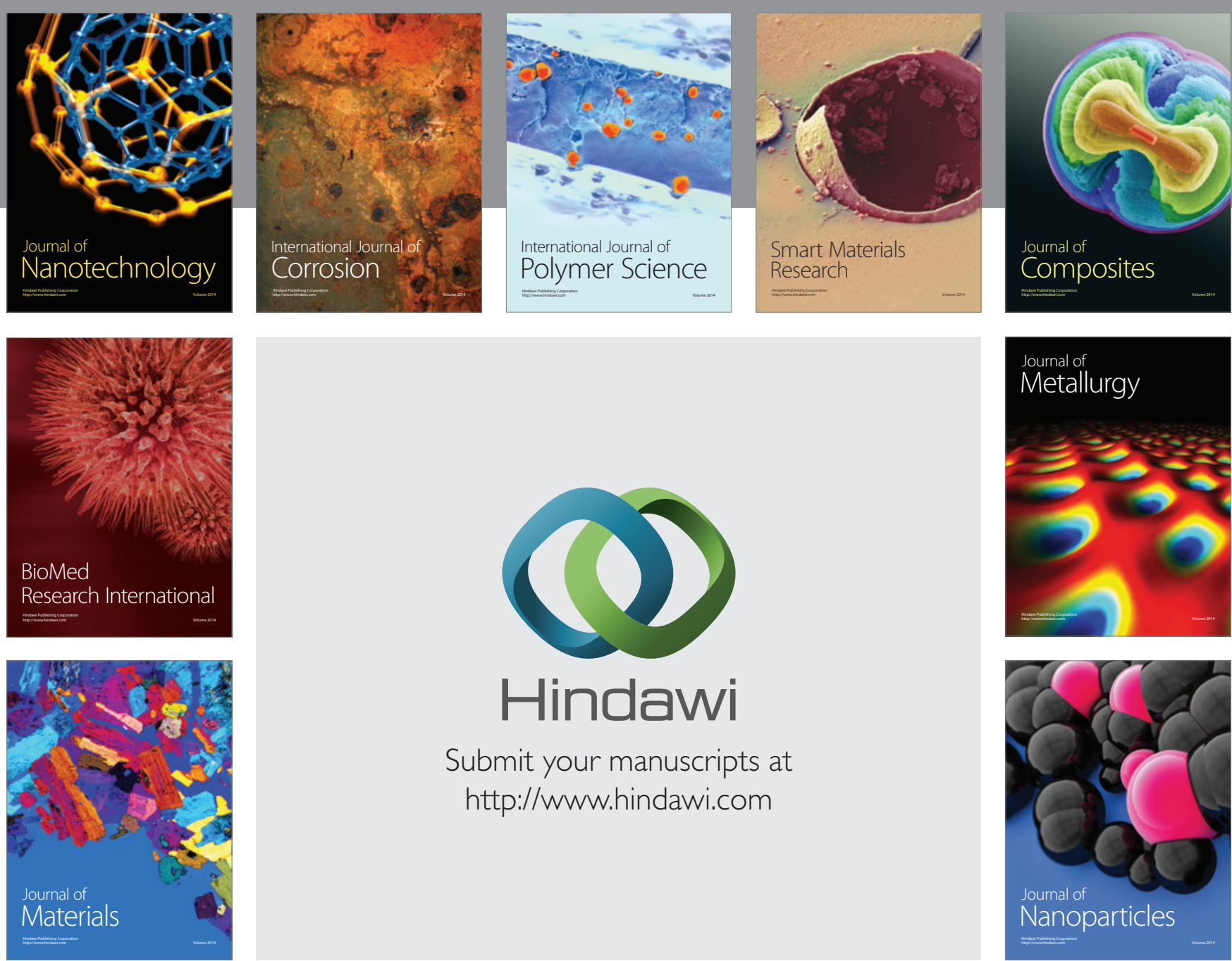

\section{Hindawi}

Submit your manuscripts at

http://www.hindawi.com

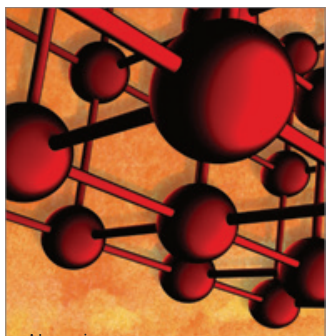

Materials Science and Engineering
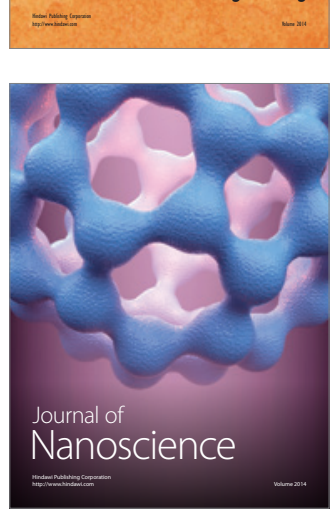
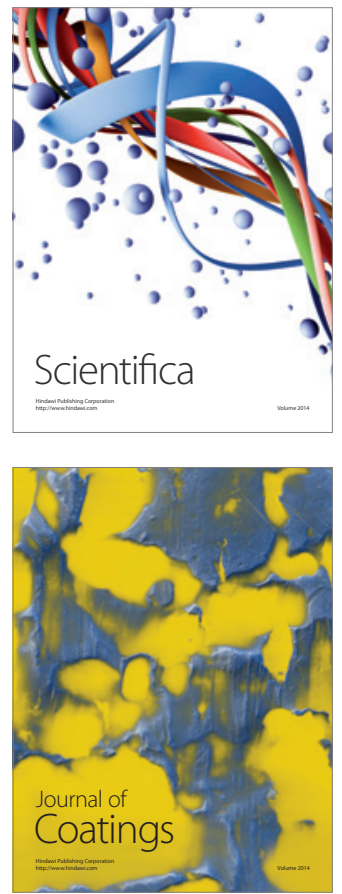
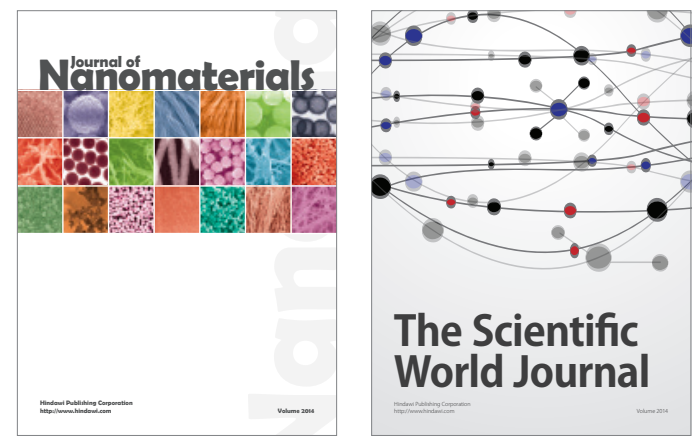

The Scientific World Journal
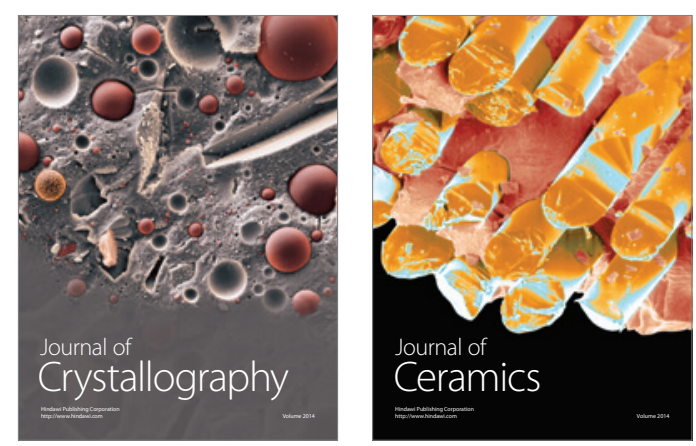
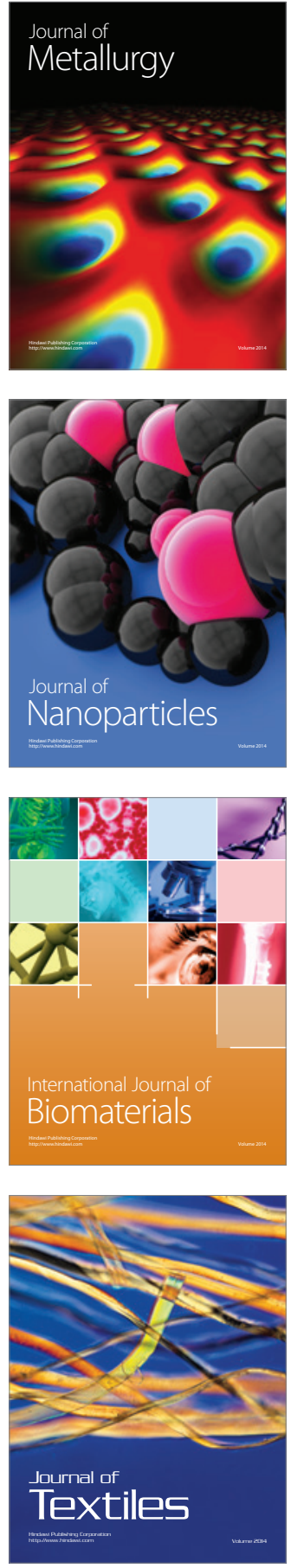